\title{
OS TEXTOS DOS DISCURSOS INSTRUCIONAL E REGULATIVO NA FORMAÇÃO EM MODELAGEM MATEMÁTICA TEMATIZANDO SOBRE OS EFEITOS NA VIOLÊNCIA ESCOLAR
}

\author{
Karolayne Santana da Silva'; Ana Virginia de Almeida Luna ${ }^{2}$ \\ 1. Karolayne Santana da Silva, Graduando em Licenciatura em Matemática, Universidade Estadual de Feira \\ de Santana, NEEMFS, e-mail: karolayneuefs@gmail_com \\ 2. Ana Virginia de Almeida Luna, DEXA, Universidade Estadual de Feira de Santana, NEEMFS, e-mail: \\ avaluna@uefs.br
}

PALAVRAS-CHAVE: Formação de professores, Modelagem Matemática, Violência escolar

\section{INTRODUÇÃO}

Neste presente resumo apresento o conceito de violência escolar e Modelagem Matemática e formação pedagógica. Deste modo, cabe destacar nas práticas pedagógicas como são importantes para a compreensão e como podem ser organizadas no que se refere aos discursos instrucional e regulativo.

Para a presente investigação foram analisados textos abordando temas de Modelagem Matemática para a formação do professor, um dos fenômenos da violência escolar, o bullying. Esta pesquisa foi é um recorte do estudo Projeto de pesquisa, Modelagem Matemática na Educação Básica: Efeitos Problematizador Sobre Violência no Contexto Escolar, desenvolvido pelo Núcleo de Estudos em Educação Matemática de Feira de Santana (NEEMFS), financiado pelo CNPq.

Neste estudo analisamos os textos durante a formação dando foco nas produções por meio de falas e planos. As discussões dos textos estão sendo desenvolvidas de forma remota utilizando as ferramentas digitais no Google Meet e Google Classrom, que compartilhamos atividades e reflexões.

Desta forma, a violência escolar é uma das principais apreensão da sociedade. Ela atinge a vida e a integridade física dos indivíduos. E, essa ação vem se tornando frequente a cada ano. E, por inúmeras formas de demonstrar desrespeito no âmbito educacional.

O bullying e o preconceito é uma das formas mais sutil de violência e frequentemente cresce o número de casos de alguns dos tipos de violência escolar.

Dentro os tipos de violência escolar, segundo Crochík e Crochík (2017), fenômenos como bullying e o preconceito parecem retratar mais diretamente a existência 
das hierarquias escolares constituídas pelos alunos. Essa relação entre os mesmo gera uma relação de hierarquização, no qual necessita de atenção.

Para Tognetta(2015), bullying é sim uma forma sutil de violência, e são as suas peculiaridades que definem o fenômeno. E, ainda de acordo com Olweus (1993), uma pessoa é vítima de bullying quando exposto, repetidamente ou ao longo do tempo, a ações negativas por parte de um ou mais sujeitos, havendo um desequilíbrio de poder na relação estabelecida entre o agressor e o agredido. Ou seja, a partir de atos repetidos pode se tornar a vida mais angustiantes e essa ação gera tormento na vida da vítima que sofre os ataques.

Dessa forma, o indivíduo não tem força de vontade para lutar contra ao que sofre, e aqueles alunos que apresentavam desempenhos satisfatórios ao sofrer com essas agressões, perdem a vontade de ir ao colégio e acabam abandonada por se sentir rejeitado pelos colegas.

Alguns alunos recorrem ao professor para pedir ajuda, porém os professores não possuem uma formação adequada para prevenir a violência entre os alunos. Tognetta (2015), afirma da falta de formação adequada para prevenir a violência entre os estudantes. É necessário que seja sejam desenvolvidas medidas para que o enfrentamento ao bullying que se estendam a totalidade dos docentes.

Apenas saber o que é bullying e preconceito, fazer campanhas durante uma semana no colégio, não adianta. A formação de professores é muito importante para a prevenção da violência escolar.

De modo, que por meio de procedimentos ofereça a comunidade escolar a aprendizagem a cooperação entre grupo heterogêneos para que se estabeleça relação entre alunos e professor.

Zeichner (1993), ressalta a importância de preparar professores que assumam uma atitude reflexiva em relação ao seu ensino e ás condições sociais que a influenciam. “A formação, portanto, deve ter o comprometimento de envolver os professores em diferentes experiências de modo que eles possam compor sua própria perspectiva". (BARBOSA,2001, p. 58).

Nesta direção, estamos entendendo que o papel da formação em Modelagem é oferecer um espaço para a troca de experiência, possíveis reflexões sobre as experiências 
com Modelagem que esse espaço pode proporcionar, a fim de que tal iniciativa, possa contribuir para a formação docente.

Desta maneira a Modelagem Matemática é, aqui, definida, como um ambiente de aprendizagem, no qual os alunos são convidados a indagar e lou investigar, por meio da matemática, situações com referência na realidade. (BARBOSA,2001, p. 31).

De acordo com D’Ambrósio (2002), a Modelagem pode ser considerada como um dos ambientes que favorece a formação inicial e continuada do professor de matemática, com ênfase em seu desenvolvimento profissional, levando em consideração situações reais.

Diante disso, a modalidade pedagógica do ambiente de Modelagem adotada em cada sala de aula pode ser regulada pelos princípios de classificação e de enquadramento, os quais dizem respeito ao discurso pedagógico de cada contexto escolar (BERSNTEIN, 2003). O princípio da classificação diz respeito a utilização para examinar as relações entre as categorias com independência. (BERSNTEIN, 2003).

Quanto ao princípio do enquadramento regula as relações dentro de um contexto, refere-se ás relações entre os que transmitem e os que adquirem o conhecimento, relações em que os adquirentes se apropriam dos princípios da comunicação legítimos. (BERSNTEIN, 2003).

Com as novas experiências vivenciadas nos espaços de formação, quando os professores deslocam os textos do curso de formação para as salas de aula há diferentes processos de recontextualização em sala de aula. A recontextualização é a transformação de um texto que, desde o campo de produção do conhecimento, sofre inúmeras transformações até que esteja pronto para uso por alunos e professores, na sala de aula. (BERSNTEIN, 2003).

O discurso pedagógico contém dois importantes contextos, o discurso instrucional que diz respeito à transmissão de competências específicas e o discurso regulativo a transmissão de princípios de ordem, relação e identidade. (BERNSTEIN, 1996, p.297(tradução nossa))

Sendo assim, levamos em consideração a formação de professores para o processo de ensino aprendizagem em Modelagem Matemática e oferecer uma formação de como lidar com uma situação de violência no âmbito escolar. Cabendo, ao professor de identificar as oportunidades no contexto escolar para desenvolver Modelagem e como fazê-la na aula de Matemática. 


\section{METODOLOGIA}

O objetivo do presente estudo é oferecer uma formação continuada aos professores em temas relacionados a Modelagem e a violência escolar, com ênfase no tema bullyig. Levando a refletir sobre as práticas pedagógicas que serve como combate ao bullying.

A pesquisa foi desenvolvida a partir de uma abordagem qualitativa, a qual de acordo com (BOGDAN E BIKLEN,1994), caracteriza-se como fonte direta do pesquisador, enfatizando o pesquisador como instrumento fundamental, focando na compreensão dos comportamentos a partir da perspectiva da investigação.

Utilizamos o modelo metodológico da linguagem de descrição, que é uma descrição sociológica de Bernstein (2000), a qual envolve uma relação dialética entre a teoria e os dados empíricos, ou seja, entre essas duas linguagens a interna (teoria) e a externa (empiria). “A linguagem de descrição possibilita movimentos cíclicos, a saber: 1) parte da teoria para iluminar a empiria (...) 2) legitima que os dados empíricos podem ampliar o campo teórico". (LUNA; SANTANA; BORTOLOTI, 2018, p. 202).

A questão formulada para a pesquisa se baseia em quais e como são produzidos os textos dos discursos instrucional e regulativo na formação em Modelagem Matemática abordando temas sobre os efeitos da Violência Escolar. Para responder a pergunta da pesquisa o plano está dividido em quatro momentos: 1) Pesquisa de materiais didáticos e estudo de conteúdos relacionados a Modelagem Matemática no contexto escolar e textos sobre violência escolar; 2) Materiais utilizados na formação continuada de professores em Modelagem Matemática no contexto de violência escolar; 3) Produção de atividades para aplicação em curso de formação continuada de professores com intuito de relacionar a modelagem no contexto escolar; 4) Textos produzidos durante a formação nas discussões no decorrer das observações.

O curso de extensão em Modelagem matemática relacionada ao bullying na Educação Básica o público alvo para a formação continuada são os professores e graduandos em licenciaturas. No que se discute diferentes textos dos discursos instrucional e sobre bullying para a formação continuada de modelagem matemática e esta formação está acontecendo no ambiente virtual do Google Meet. Serão divididos grupos para a realização da atividade. Para a resolução foram discutidos os textos relacionado ao bullying e a Modelagem Matemática. 


\section{ANÁLISE DE DADOS}

A análise de dados ocorreu a partir de materiais utilizados na formação continuada de professores em Modelagem Matemática no contexto de violência escolar em que os professores estão participando numa plataforma digital. No Google Meet, acontece encontros online, no qual todos do curso de extensão participam para socializar por vídeo conferência.

Para isso, foram discutidos os casos de modelagem em conjunto ao bullying.Com o objetivo de combater o bullying relacionando com a nossa realidade, com outras ciências ou qualquer outra área, mas com intuito de oferecer a possibilidade de resolver a questão ou situação-problema proposta por meio da matemática, para na formação o professor reconhecer o papel da matemática na sociedade, com uma questão social tão relevante.

De acordo com Barbosa (2009), cabe ao professor identificar as oportunidades no contexto escolar para desenvolver Modelagem e como fazê-la. Para tanto, o autor apresentou a noção de "casos" para denominar as diversas formas de organizar atividades de Modelagem na sala de aula, conforme as responsabilidades são compartilhadas entre professor e alunos. (BARBOSA,2001, 2009).

A análise teve como ênfase na produção dos grupos que de forma relacional construíram a resolução por caminhos já vivenciados na produção e reflexão dos textos e atividades. Dessa forma, foi disponibilizado um link da atividade para que cada grupo pudesse começar a elaborar e produzir a situação-problema proposto do Caso 1 .

Para elaboração da atividade foi apresentado um texto sobre fenômeno bullying, que fornece dados sobre o índice de bullying nas escolas. Logo, foram apresentados outras questões propostas com o objetivo de aproximar o professor-participante da formação ao tema, propor uma formação e estabelecer ferramentas para o enfrentamento do bullying em âmbito escolar.

$\mathrm{Na}$ primeira questão proposta analisaram os dados oferecidos pelo texto e resolveram a pergunta envolvendo a matemática e cada um dos integrantes contribuíram e chegaram à conclusão que aproximadamente 195 mil alunos sofreram bullying no ano de 2015. A questão proposta envolveu a matemática com outras áreas do conhecimento, ou seja, a Modelagem Matemática já estava inserida na situação apresentada. Desta forma, as questões foram voltadas para o Caso 1 de Modelagem. 


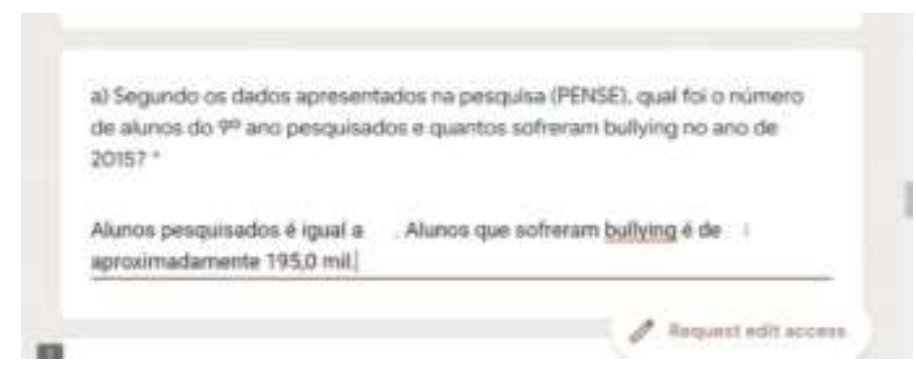

Fonte: Dados coletados Curso de Extensão Online, Polo em Feira de Santana NEEMFS,2020.

É possível observar que a Modelagem Matemática acontece por meio de desenvolvimento de Caso 1, 2 e 3. No Caso 1, o professor apresenta a situação-problema e discute com o alunos, estes são organizados em grupos que buscam produzir uma resolução tendo acompanhamento do professor, os grupos de alunos apresentam a resolução para discussão em turma e o professor formaliza de estratégias por tópicos matemáticos (BARBOSA, 2009).

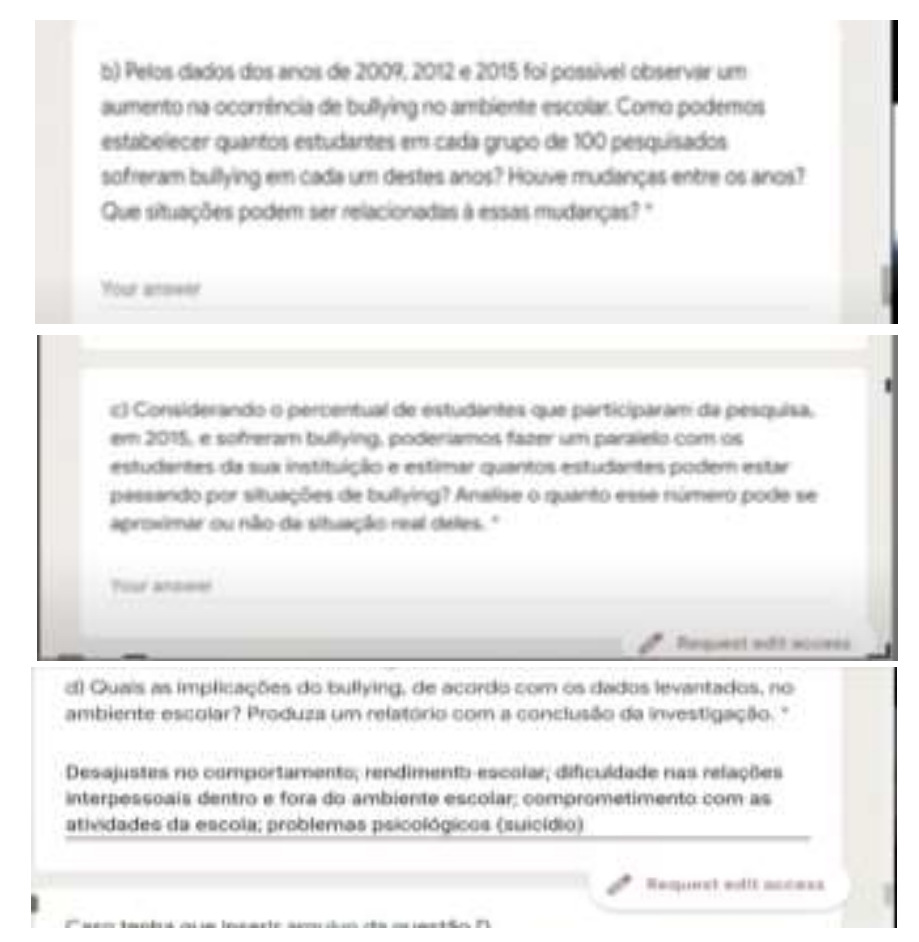

Fonte: Dados coletados Curso de Extensão Online, Polo em Feira de Santana NEEMFS,2020.

Como apresentado na questão "b e c" foram propostos aos grupos levantar informações sobre os dados das suas instituições, como este levantamento não era o real foi apenas estimativa, a atividade ainda estava toda com o professor e o estudante em cada etapa do processo, foi uma atividade de caso 1, de crescimento do bullying. 
Na proposta de atividade do Caso 2, o formador apresentou a situação-problema relacionado ao bullying e os participantes coletaram os dados e produziram a resolução. Dessa forma, os problemas são orientados a levantar informações sobre o tema e formular e resolver os problemas. Por fim, socialização os resultados da resolução da situação dada.

No Caso 3, os participantes em formação escolheram o tema e coletaram informações, formularam e resolveram as situações-problema. No final, cada participante e os seus pares socializaram com os demais grupos as questões propostas sobre as implicações do bullying, por meio da apresentação de um relatório investigativo, com a a discussão e reflexão no grupo do núcleo online.

Sendo assim, é importante para as reflexões de como desenvolver projetos de prevenção ao antibullying no contexto escolar (TOGNETTA, 2015), a realização de ações colaborativas. Ressaltando, sobre a importância da formação continuada observada aos acompanhar as produções dos textos do discurso instrucional de modelagem tematizando bullying, foi possível nos aproximar de como elaborar e planejar projetos com ações voltadas ao fenômeno bullying. Dessa forma, o Curso de Extensão ofereceu ferramentas e uma proposta para uma formação continuada relacionando a Modelagem Matemática e o bullying, levando em consideração como contribuir quando se deparar com uma situação de violência no âmbito escolar.

\section{REFERÊNCIAS}

BARBOSA, J. C. Modelagem matemática: Concepções e Experiências de futuros Professores. 2001 p 31. Tese (doutorado) elaborada junto com o programa de Pós Graduação em Educação Matemática, Universidade Estadual Paulista. Rio Claro,2001.

BARBOSA, J.C.Integrando Modelagem Matemática nas práticas pedagógica. Educação Matemática em Revista, São Paulo, v.26, p.17-25, 2009.

BERNSTEIN, B, A Estruturação do Discurso Pedagógico, Coleção: Ciências Sociais da Educação, Petrópolis, 1996.

BERNSTEIN, B, Classe, código e controle: A estruturação do discurso pedagógico. Londres: Routledge,2003.

BOGDAN, R.; BIKLEN, S. Investigação Qualitativa em Educação. Porto: Porto Editora, 1994.

BOULLON(1997), 
CROCHIK, J.L; CHOCHIK, N. Bullying, preconceito e desempenho escolar: uma nova perspectiva. São Paulo: Benjamin Editorial,2017.

LUNA. A.V. A Modelagem Matemática na Formação Continuada $e$ a Recontextualização Pedagógica desse Ambiente em Salas de Aula. 2012. p 21 e 25. Tese (Pós-Graduação) em Ensino Filosofia e História das Ciências-Universidade Federal da Bahia e Universidade Estadual de Feira de Santana, Salvador,2012.

LUNA, A. V. A.; SANTANA, F. C. M.; MENDUNI-BORTOLOTI, R. D. A linguagem de descrição: uma possibilidade de fazer pesquisas no campo da educação matemática. Educação Matemática Pesquisa, 2018.

OLWEUS, D. Bullying at school: What we know and what we can do. Malden, MA: Blackwell Publishing, 1993.

TOGNETTA, L.R.P.Bullying: quem tem medo: uma proposta de implementação de um programa em que a convivência entre as crianças na escola seja um valor.1.ed.Americana, SP:Adonis,2015.

ZEICHNER, K. M. A Formação Reflexiva de Professores, Ideias e Práticas. EDUCA, Lisboa, 1993. 